\title{
GeoInformatica welcomes a new co-editor-in-chief
}

\author{
Shashi Shekhar ${ }^{1}$ - Elisa Bertino ${ }^{2}$
}

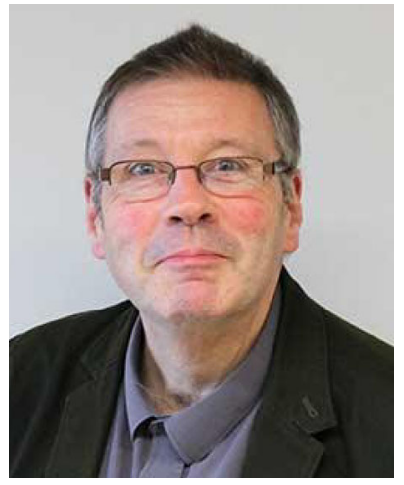

We are pleased to welcome Professor Christopher Brunsdon as GeoInformatica's new co-Editor-in-Chief. Chris is a Professor of Geocomputation and the Director of the National Centre for Geocomputation at Maynooth University in Ireland, which is the principal centre for geocomputation and spatial analyses in Ireland. He received his BSc degree in Mathematics from Durham University and MSc degree in Medical Statistics, the $\mathrm{PhD}$ degree in Geography from Newcastle University. Previously, he was a Professor of Human Geography at the University of Liverpool in the UK, and before this he worked in the Universities of Leicester, Glamorgan and Newcastle.

Chris' research interests include spatial statistics, data science and spatial analysis. He has co-authored more than 200 research papers in peer-reviewed journals, books, conferences and workshops. He is one of the developers of Geographically Weighted Regression (GWR) which provides a local modelling approach to make spatial analysis opposed to the previous global models of relationships. He also coauthored a book on "Geographically Weighted Regression: The Analysis of Spatially Varying Relationships" (Wiley, 2002, ISBN: 978-0-471-49,616-8) which provides a comprehensive coverage on GWR.

Chris is also interested in the development of spatial tools that can be used in health geography, crime pattern analysis and environmental analysis domains. $\mathrm{He}$

Shashi Shekhar

shekhar@umn.edu

1 University of Minnesota, Minneapolis, MN 55455, USA

2 Department of Computer Science, Purdue University, West Lafayette, IN, USA 
advocates the use of open source software, and reproducible methods, mainly via the R Statistical Programming Language. Recently, he co-authored a book as "An Introduction to R for Spatial Analysis and Mapping" (Sage, 2015, ISBN: 978-1-446$27,295-4)$ to provide information on open source software use for spatial analysis.

Shashi Shekhar

Elisa Bertino

August, 2016 